\title{
Improving the quality of distance education through online learning
}

\author{
Robyn Benson \\ Monash University, Australia
}

\begin{abstract}
A range of factors influences decisions about the quality of distance learning, including the theoretical perspectives of learning which are supported, the context of the learning experience, the approaches used for design, development, teaching, assessment and evaluation, the systems and infrastructure available, and the nature of the decision-making process. While developments in educational technology have provided powerful new tools to support learning and teaching, and raised issues about staff development to encourage their appropriate use, this paper focuses on three key concepts (dialogue, reflection and iteration), arguing that they play a pivotal role in determining the quality of the student learning experience at a number of different levels, and that they are especially valuable for considering the quality of the online distance learning experience.

After an initial discussion on the nature of quality in relation to contemporary views of learning and teaching, the paper discusses the above key concepts and applies them to evaluation studies which were undertaken at Monash University as innovations in online distance learning were introduced at subject level. The studies illustrate the importance of these concepts in improving the student learning experience, as well as their role in improving design, development and teaching, and their relevance to assessment and evaluation.
\end{abstract}

Key words: dialogue, reflection, iteration, online learning

\section{INTRODUCTION}

It is not enough to insist upon the necessity of experience, or even the activity in experience. Everything depends on the quality of the experience which is had (Dewey, 1972, p.27).

The original version of this chapter was revised: The copyright line was incorrect. This has been corrected. The Erratum to this chapter is available at DOI: 10.1007/978-0-387-35700-3_33 


\subsection{Perspectives on the student learning experience}

Constructivism and phenomenography may be seen as the dominant theoretical perspectives currently informing student learning research in higher education (Biggs, 1999). While they have characteristics in common, both conceptualising learning as an internal change influenced by the external world and requiring the active engagement of the learner, they are different in that a phenomenographical perspective sees meaning as constituted 'through an internal relationship between the individual and the world ... [whereas constructivism involves] separation between the individual and the world. Knowledge is brought in from the outside or constructed on the inside. Each of these perspectives is dualistic; there are two elements: the student and the world' (Prosser \& Trigwell, 1999, pp. 1213).

Notwithstanding this difference, it would appear that if concepts associated with either of these perspectives are supported, then determining the quality of the student learning experience requires strategies that will allow consideration of the internal changes involved in learning. Other notions related to experience and education, including those in the intellectual lineage of Dewey (1972), those which draw on the social context of knowledge, and those which recognise the affective aspects of the learning process (Boud, Keogh \& Walker, 1985) are also relevant in this context.

\subsection{Identifying the quality of the learning experience}

Recognition of the complications caused by the subjective nature of the concept of quality are not new: the values used to identify it, the criteria used to measure it, and judgements about the extent to which it has been achieved, are all open to interpretation. A decade ago, a project to investigate quality in relation to distance education in Australia noted that two characteristics affecting judgement about the quality of distance education were that links to a general position about judging the quality of education may privilege certain values above others, and that the legitimacy of the judgement may be challenged by those that do not have power to influence the judgemental process (Nunan \& Calvert, 1992, Nunan, 1993).

A commonly used practical definition of quality is that of fitness for purpose (Ball, 1985). While this has appeal in being general enough to fit all circumstances, the issue of interpretation remains: "Quality" in the university context has a lot to do with the quality of learning and the quality of learning has a lot to do with the qualities of different ways of seeing.' (Bowden \& Marton, 1998, p. 219). 
Discussions about quality at system, policy, institutional or government level usually involve judgements by decision-makers based on performance against identified indicators, related to quality assurance in terms of improvement and accountability (Bowden \& Marton, 1998). This paper focuses on three concepts (reflection, dialogue and iteration), familiar in education from a number of theoretical perspectives, which may be used to ensure the quality of learning at subject level, based on the understandings of learning outlined above. Although they are by no means the only concepts of importance (consideration of learner characteristics, context, intent, activity and support may be seen as among other essential elements), they are useful for identifying core information which can be fed into broader decisions about quality in relation to the online distance learning experience. Laurillard (2002) incorporates all three in her conversational framework which provides both a principled teaching strategy and a framework for the ongoing improvement of university organisational infrastructure. It is proposed here that the application of these concepts to distance learning and teaching, and their extension to design, development and evaluation, are both facilitated by and necessary for determining quality in an online context, given the team environment usually involved in resource-based learning.

The following discussion focuses particularly on communication as a key attribute of the online environment, and for the reasons outlined above, assumes the following:

- that as quality is a value judgement, decisions about it require consensus

by key stakeholders on fitness for purpose;

- that quality in learning and teaching in higher education requires encouragement of individual or social construction of meaning (or a deep approach to learning, or equivalent) and may be confirmed by merging understandings of learners and teacher;

- that quality in design, development and evaluation requires input and consensus by key stakeholders; and

- that the online environment adds considerably to distance education.

\section{DIALOGUE}

Dialogue can be seen as essential in distance education, both for developing engagement in meaningful learning and for reducing isolation (Morgan, 1993). Prior to the opportunities now available for online learning, Evans \& Nation (1989) noted the fundamental value of dialogue for enhancing quality in learning to support construction of meaning by learners, and also for enhancing discourse amongst teachers and researchers. 
They defined dialogue as involving 'the idea that humans in communication are engaged actively in the making and exchange of meaning, it is not merely about the transmission of messages' [their italics, p.37]. As indicated earlier, the concept of mutually developed meanings is important in relation to quality, given the implications of "different ways of seeing" Bowden \& Marton, 1998, p. 219): in the learning-teaching process it allows for accessing and developing internal change through shared understanding; in design, development and evaluation it allows for common evolving understandings as learning activities are developed and refined.

Increasing the capacity for appropriate use of dialogue may therefore be seen as increasing the potential for a quality learning experience. In a distance learning situation, characterised by the 'quasi-permanent separation of teacher and learner throughout the length of the learning process' (Keegan, 1996, p. 50) the use of online learning to facilitate one-to-one and one-to-many communication thus has important implications for quality, though it is acknowledged that the way these opportunities are used for teaching is also important. The availability of guidelines and models to help staff with online teaching (for example, Salmon, 2000) is invaluable. Some examples relating to the introduction of online components to subjects developed at Monash University follow. In each case, dialogue may be seen as adding to the quality of the distance learning experience in ways not possible before online learning was available.

Preliminary use of computer mediated communication (CMC) in 1997 by undergraduate Social Work students and their lecturer (all of whom had limited computer experience), demonstrated the value of dialogue for developing students' analytical and negotiating skills (despite problems created by access and technical difficulties) and also its value for reducing isolation:

In terms of $\mathrm{DE}$, it is a brilliant medium for reducing isolation, getting prompt feedback from the lecturers and sharing with peers (Student comment quoted in Benson \& Hewitt, 1998, p. 79).

In this subject, weekly assessable online tutorial tasks (with specified assessment criteria) were provided in the students' print materials, with an offline alternative for students unable to participate online. Evaluative comments were received from all immediate stakeholders: online students, offline students, the lecturer, the help desk operator, and the project officer responsible for the operation of the CMC system. In addition, CMC messages were analysed using the typology developed by Mason (1991). The pedagogical advantages of the guided collaborative experience clearly outweighed the problems for those able to participate online. Even the offline students gained some benefit as a result of the regular 'equivalent' 
offline tasks which resulted in increased feedback from the lecturer (Benson \& Hewitt, 1998).

Similar results emerged in the initial offering in 1999 of a fully online graduate Law subject (The Law of the Internet) which had not previously been taught at a distance. The subject consisted of ten modules, each including a set of compulsory online tasks, along with a discussion topic to be debated at tutorial group level. Criteria to guide appropriate online contributions were explained and minimum participation requirements specified. Access and technical difficulties remained problematic but the online component added a dimension not available when the subject was taught face-to-face:

... Because we have to perform tasks and participate in discussions each week we are forced to think about the material. This is a great plus (Student comment quoted in Benson \& de Zwart, 2000, p. 431).

The off-campus offering provided access to students who could not have otherwise enrolled while its availability online simultaneously allowed immersion in the content of the subject, and dialogue about the issues which emerged, strengthening achievement of the intended learning outcomes.

A further example in 2000 involved a $\mathrm{WebCT}^{\mathrm{TM}}$ site developed for an introductory Accounting subject offered in Australia to on-campus and offcampus students (including Year 13 school students), and to overseas students in Singapore, Malaysia and Hong Kong. Students were provided with opportunities to discuss problems and solutions associated with resources available on the site and in accompanying print materials (Benson, Hardy \& Maxfield, 2001). Online dialogue increased the immediacy of contact between teacher and students, facilitating and extending mutual understanding, and adding a new international aspect to the distance learning environment. Technical difficulties had largely been eliminated through the use of WebCT, though problems relating to administration, preparedness of staff and students, and the need for structured use of the bulletin board remained. However, the online component provided participating students with the opportunity to grapple with issues through the encouragement of multiple narratives. Advantages were not confined to active participants: evaluative comments from some of the 'lurkers' also referred to the assistance to their learning which resulted from viewing the contributions of others. 


\section{DIALOGUE AND REFLECTION}

Adding the concept of reflection to that of dialogue offers a powerful new tool for creating and verifying quality in learning. Both of these ideas are encompassed in social theory perspectives of the dialogical nature of education. The contribution of Freire (1972) remains influential in conceptualising the teacher-student partnership in the development of knowledge through dialogue, reflection and action. Related ideas associated with action research (Carr \& Kemmis, 1986) and reflection-in-action (Schon, 1987), with their implications for improvement via reflection in the midst of action, have relevance to learners and teachers, as well as to designers, developers and evaluators. Other useful perspectives on reflection include its role in exploring both the intellectual and affective components of experience to enhance learning (Boud, Keogh \& Walker, 1985 ) and its importance as a stage in learning as expressed in Kolb's experiential learning cycle (Kolb, 1984). Distance education online offers increased opportunities to combine reflection and dialogue for developing student engagement in learning by allowing these activities to occur throughout the semester. These concepts also provide an approach for reaching agreement about quality by the range of stakeholders involved in learning design.

In the introductory Accounting subject the concept of multiple narratives through reflection-in-action was used to improve student learning by encouraging learners to challenge the assumptions of traditional Accounting pedagogy, and also to encourage them to reflect on and discuss the teaching of the subject as a means of contributing to its improvement (Benson, Hardy $\&$ Maxfield, 2001). Dialogue and reflection were taken a step further by the teacher and educational designer (evaluator) involved in the subject by then employing these processes to consider information from a range of sources in evaluating the subject. Reflection and dialogue were also used for evaluation in the online Law subject (Benson \& de Zwart, 2000): a sample of the student group was emailed on a rotating basis throughout the semester and asked to reflect on their experiences in that week, and to respond as if writing a letter or reflective journal entry. This process was complemented by monthly reflective memos from the lecturer and an interview with her at the end of the semester.

\section{DIALOGUE, REFLECTION AND ITERATION}

The availability of an online learning environment for distance students, allows iteration to be easily added to dialogue and reflection to create the 
iterative dialogue which Laurillard (2002) conceives as a principled teaching strategy, enabling convergence of ideas to generate meaning. In addition, when iteration is acknowledged as having an important role in design, development and evaluation it permits ongoing subject development based on feedback, reflection and dialogue as a common view of quality evolves. A cyclical, iterative approach to design and development also allows for continual adjustment to specific circumstances and student cohorts. When added to dialogue and reflection, iteration, in effect, provides a quality assurance mechanism to test for fitness for purpose. In the introductory Accounting subject dialogue, reflection and iteration provide the central strategies for ongoing refinement of the subject to meet the learning needs of the students in the international classroom (Benson, Hardy \& Maxfield, 2001).

\section{ASSESSMENT AND EVALUATION}

The online environment in distance education also adds considerably to the potential for dialogue, reflection and iteration (individually or in combination) to improve the quality of assessment. For example, opportunities for iterative dialogue facilitate formative assessment, continuous assessment and group assessment (Thorpe, 1998), while the capacities of the electronic learning environment also provide for a range of authentic, situated learning tasks, involving reflection and metacognition. A previous study at Monash University (Benson, 1997) had indicated both the need and opportunity to enhance the learning and assessment of off-campus students by managing a number of elements of the communication process. The online environment contributes markedly to the ease of implementing this approach: the Social Work and Law subjects mentioned earlier introduced assessable collaborative learning activities and both lecturers commented on evidence of the increased depth of learning which resulted. In the Accounting subject, potential for online assessment is now considered as essential in the next phase of the subject's iterative development to extend to all enrolled students the enhanced learning outcomes which result from online participation.

The use of dialogue and reflection in the Law and Accounting and subjects, as described earlier, has also illustrated the potential for online evaluation both directly in relation to learning, and indirectly for design, development and evaluation, while also highlighting its necessity in terms of quality assurance. These processes illustrate the potential for iteratively improving the quality of the online distance learning experience at subject level, but the gains may be limited if there is not the capacity to share and 
influence quality decisions at university level. However, Laurillard (2002, p.232) envisages that evaluation of this kind can have a role at a whole university level where lessons learned are shared:

... [as] part of the iterative process that delivers specific information to the innovative design stage, and delivers the more general lessons learned to the knowledge-sharing stage. The latter may take the form of evaluation reports available on a central website, recommendations for policy changes, or developed design practice embodied in guidelines or design templates for others to use. The data collected will come from detailed case studies, learning experiments, observation studies and intensive interviews, all designed to challenge the design against use, and to inform the re-design process about learners' needs...

\section{CONCLUSION}

The practical application of approaches which include dialogue, reflection and iteration, supported by a number of theoretical perspectives, has the intrinsic capacity to improve the experience of distance learners both by improving learning, teaching and assessment, and by assisting design, development and evaluation, allowing continued adjustment to respond to the complexities of the environments in which these activities take place. In improving the quality of distance learning, the online environment offers increased potential for improving learning via reflective iterative dialogue, while necessitating and permitting an incremental approach to design, development and evaluation for quality assurance.

This paper has provided some examples to illustrate the benefits to distance education offered by simple initiatives in online learning. The access and technical difficulties mentioned in the first two examples have subsequently become less problematic as university systems and infrastructure have improved. However, it was notable that even when these problems existed, clear improvements to learning were reported by staff and students. Online learning offers opportunities for student support and for convergence of views to judge fitness for purpose, characteristics which are especially important when opportunities for face-to-face contact are limited.

\section{REFERENCES}

Ball, C. (1985). What the hell is quality? In D. Urwin (Ed.), Fitness for purpose: essays in higher education. Guildford: SRHE \& NFER-Nelson. 
Benson, R. (1997). Approaches to assessing open and distance learners. In T. Evans, V. Jakupec \& D. Thompson (Eds.), Research in Distance Education 4: revised papers from the fourth Research in Distance Education (RIDE) Conference, Deakin University 1996. 102-114 Geelong: Deakin University Press.

Benson, R., Hardy, L. \& Maxfield, J. (2001) The international classroom: using reflective practice to improve teaching and learning. In G. Kennedy, M. Keppell, C. McNaught \& T. Petrovic (Eds.) Meeting at the Crossroads. Proceedings of the $18^{\text {th }}$ Annual Conference of the Australasian Society for Computers in Learning in Tertiary Education (ASCILITE). 83-92. Melbourne: Biomedical Multimedia Unit, The University of Melbourne.

Benson, R. \& Hewitt, L. (1998) Breaking down the barriers: developing online communication in an offline environment. In $R$. Corderoy (Ed.), ASCILITE '98. Flexibility: the next wave? Proceedings of the $15^{\text {th }}$ Annual Conference of the Australasian Society for Computers in Learning in Tertiary Education (ASCILITE). 75-85. Wollongong: University of Wollongong.

Benson R. \& de Zwart, M. (2000) The experience of online learning: evaluating the effectiveness of an innovation in web-based legal education. In R. Sims, M. O'Reilly\& S. Sawkins (Eds.), Learning to Choose: Choosing to Learn. Proceedings of the $17^{\text {th }}$ Annual Conference of the Australasian Society for Computers in Learning in Tertiary Education (ASCILITE). 425-434. Lismore: Southern Cross University Press.

Biggs, J. (1999). Teaching for quality learning at university. Buckingham: SRHE \& OUP.

Boud, D.J., Keogh, R. \& Walker, D. (Eds.) (1985). Reflection: turning experience into learning. London: Kogan Page.

Bowden, J. \& Marton, F. (1998). The university of learning: beyond quality and competence in higher education. London: Kogan Page.

Carr, W. \& Kemmis, S. (1986). Becoming critical: education, knowledge and action research. Lewes: Falmer Press.

Dewey, J. (1972). Experience and education (originally published in 1938 by Kappa Delta Pi). New York: Collier.

Evans, T. \& Nation, D. (1989). Dialogue in the theory, practice and research of distance education. Open Learning, 4 (2): 37-46.

Freire, P. (1972). Pedagogy of the oppressed. Harmondsworth: Penguin.

Keegan, D. (1996). Foundations of distance education ( $3^{\text {rd }}$ ed.). London: Routledge.

Kolb, D. (1984). Experiential learning. Englewood Cliffs, NJ: Prentice-Hall.

Laurillard, D. (2002). Rethinking university teaching: a conversational framework for the effective use of learning technologies $\left(2^{\text {nd }} e d\right)$. London: Routledge.

Mason, R. (1991). Analysing computer conferencing interactions. Computers in Adult Education and Training, 2 (3): 161-173.

Morgan, A. (1993). Improving your students' learning: reflections on the experience of study. London: Kogan Page.Nunan, T. \& Calvert, J. (1992). Report of the project to investigate quality and standards in distance education. University of South Australia and Deakin University.

Nunan, T. (1993). The quality of distance education: what does it mean and how can it be judged? In T. Nunan (Ed.), Distance education futures: selected papers from the $11^{\text {th }}$ Biennial Forum of the Australian and South Pacific External Studies Association. 483499. Adelaide: University of South Australia.

Nunan, T. \& Calvert, J. (1992). Report of the project to investigate quality and standards in distance education. University of South Australia and Deakin University.

Prosser, M. \& Trigwell, K. (1999). Understanding learning and teaching: the experience in higher education. Buckingham: SRHE \& OUP.

Salmon, G. (2000). E-moderating. London: Kogan Page. 
Schon, D.A. (1987). Educating the reflective practitioner. San Francisco: Jossey-Bass.

Thorpe, M. (1998). Assessment and 'third generation' distance education. Distance Education, 19 (2): 265-286. 